COMMUNICATIONS

\section{My Trip to the XXI Congress of the European Association for Cranio-Maxillo-Facial Surgery}

\author{
Soo-Hyung Han \\ Department of Plastic and Reconstructive Surgery, St. Vincent's Hospital, \\ The Catholic University of Korea School of Medicine, Suwon, Korea
}

\author{
Correspondence: Soo-Hyung Han \\ Department of Plastic and Reconstructive Surgery, St. Vincent's Hospital, The Catholic University of \\ Korea School of Medicine, 93 Jungbu-daero, Paldal-gu, Suwon 442-723, Korea \\ Tel: +82-31-249-7114, Fax: +82-31-241-0005, E-mail: h1051504@ naver.com \\ No potential conflict of interest relevant to this article was reported.
}

Received: 5 Aug 2012 • Revised: 6 Aug 2012 • Accepted: 7 Aug 2012 pISSN: 2234-6163 • elSSN: 2234-6171

http://dx.doi.org/10.5999/aps.2013.40.3.295 • Arch Plast Surg 2013;40:295-296

Copyright (C) 2013 The Korean Society of Plastic and Reconstructive Surgeons This is an Open Access article distributed under the terms of the Creative Commons Attribution Non-Commercial License (http://creativecommons.org/licenses/by-nc/3.0/) which permits unrestricted non-commercial use, distribution, and reproduction in any medium, provided the original work is properly cited.

It has already been a month since I went to Dubrovnik, Croatia to attend the congress for the European Association for Cranio-MaxilloFacial Surgery (EACMFS), but I still treasure the memories I made there. I can still remember the excitement designing the poster last winter, the joy I felt when my poster was accepted, the five days I spent in Croatia, full of wonder and an eagerness to see a whole new world, and the warmth I felt from my mother as we traveled around Croatia afterwards together. Even as I write about my experiences, it feels like I am back there again.

The EACMFS was founded in 1972. The first congress was held in Ljubjana, and it has been held once every two years ever since. Although the congress focuses primarily on cosmetic surgery in Europe, trends in Asia in the field of craniofacial surgery are also discussed and represented. I had first become interested in the

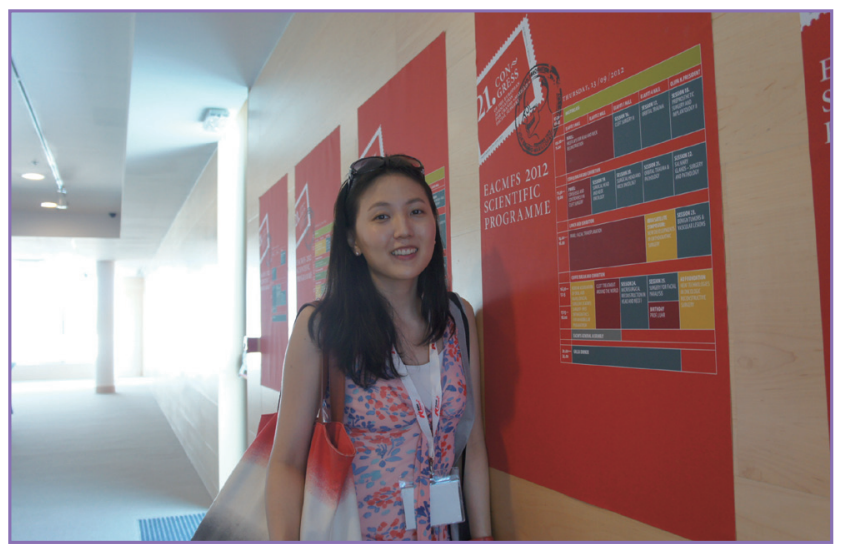

Fig. 1. In front of the poster for the congress program. conference after someone senior to me in my department attended the conference two years ago. In recent years, Japanese and Korean physicians have prepared special presentations. I was able to meet many Korean professors, particularly in the session run by Korean doctors on the treatment of hemifacial microsomia and microtia. I was very impressed that Korean professors took part in more than just one or two presentations. It was obvious that Korea's position is well-established in the fields of jaw surgery and congenital facial deformity. Although the E-poster I had made was not the greatest, I was still proud that it was shown on both of the presentation screens. As it was not a paper poster but a computer presentation, I could update the presentation based on other physicians' questions or comments.

The conference was held at the Valamar Lacroma Hotel: a large resort overlooking the Adriatic Sea. However, the size of the conference hall was not very large. It was with excitement and a sense of expectation stirred by the colorful magazines and brochures I had read and the fact that it was my first time abroad for an international conference that I went to Croatia. When I arrived, I was a bit puzzled by the simplicity. However, even though the conference grounds were not large, I was impressed when I saw the international cosmetic surgery physicians, male and female, young and old, freely and uninhibitedly consulting and networking with each other. In addition to the academic sessions, we were able to relax in a lighter atmosphere during some of the prepared activities. Among the European participants, there were some physicians who, similar to me, came from the non-English speaking world. Even though we weren't able to communicate completely, it was enjoyable trying to converse with each other. During the coffee breaks, instead of cakes or cookies, we munched on fresh fruit to our heart's content. It was good to see some of the older westerners innocently happy. Even though I enjoyed all of these simple pleasures, there was one part that I look back on with some regret. My English skill is such that I could not understand one hundred percent of the discussion and presentations. I was very thankful when a kind British doctor took my question in broken English and spoke slowly when he answered me. However, later when I listened to other presentations in faster English I was

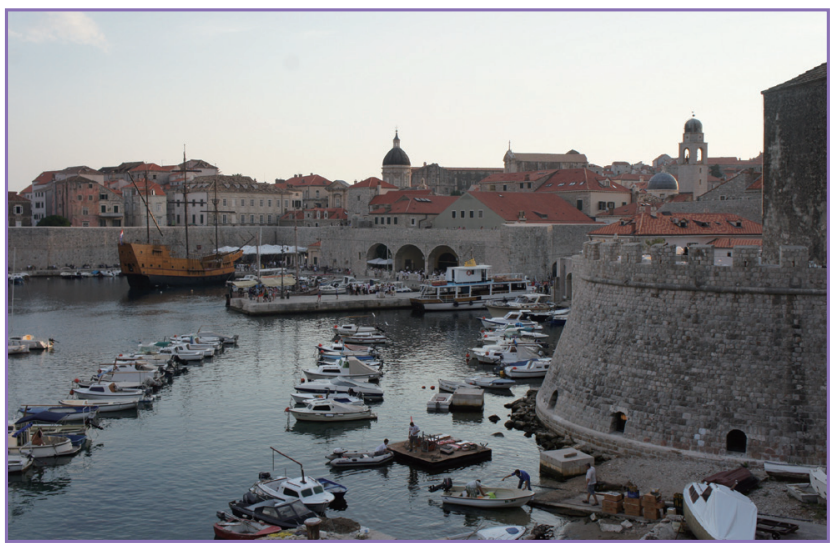

Fig. 2. Dubrovnik (from outside the castle walls). 
frustrated and discouraged.

After the congress-sponsored activities, my mother, who had been touring the surrounding area by herself during the day, joined me and we walked around the old town of Dubrovnik together. The old town had been designated as a cultural heritage site by UNESCO. The seaside fortress, often called the 'Pearl of the Adriatic', was one of the places I had wanted to come visit since I was a cosmetic surgery student. Perhaps because of that it seemed more beautiful. When I was freshman I took a train trip throughout Europe and met another European student in the same car. Even though we both spoke broken English we quickly became friends. This friend was from Croatia. He spent the spent the whole night telling me about how beautiful his country was. At that time I felt sorry because I had no idea where in Europe Croatia or Dubrovnik was located. After I came back from trip I looked it up and realized Dubrovnik was a sea-side city wellknown by European tourists. Even in the sweltering summer heat, tourists came from all over Europe. As Italy is nearby, Italian families, couples, and groups of friends could be seen everywhere. When I heard that it normally takes travelers approximately two weeks to fully see and enjoy the whole area I was rather jealous that they had so much time.

On the first evening of the congress, a folk performance took place in a corner of this beautiful city as part of the opening ceremony. The performance was so interesting it felt like we had suddenly got tickets and were able to watch an expensive performance. The president of Croatia also attended. Even though I had not known the president would be coming, I was impressed when he came accompanied with only a small retinue. After the performance as we explored the old town, our feet made a lovely sound tramping over the well-worn cobblestones that covered all the roads and walkways. Even though it was evening and there was not much illumination, it was bright enough to easily walk around the town.

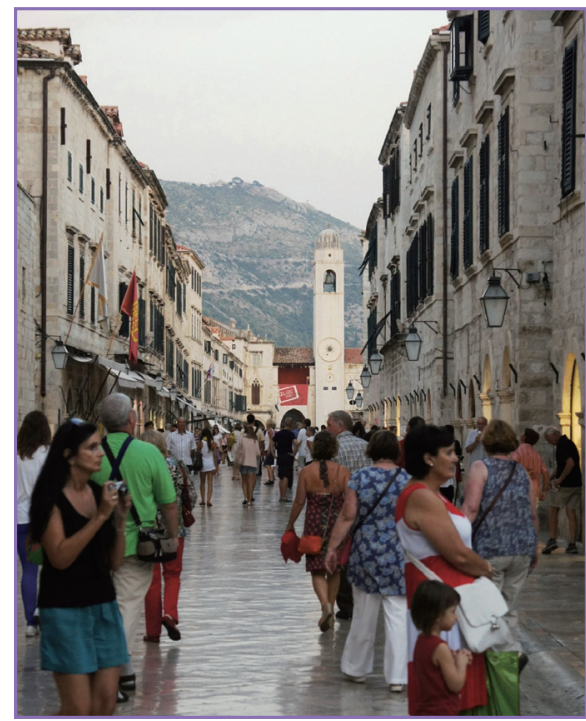

Fig. 3. Dubrovnik town.
One of my most precious memories from the time I spent in the old town was a one and a half hour tour of the castle that I went on with my mother. My mother had been worried that her knees would hurt climbing the castle's many stairs, but as if her feet were driven by a motor she walked with much firmer steps than I. Last year she had had surgery in her knees but since last winter she had been exercising every day at home on her stationary bike so that she could travel with me. I was thankful and touched that she had wanted to come with me, her eldest daughter, even though I often had not stayed in touch or spent much time with her before. Some of my most beautiful memories are our eyes smarting from gazing at the dazzling blue sea below the castle walls, watching some of the young people without an ounce of fear jumping off the steep cliffs into the water below, and drinking coffee together with my mother and listening to the live piano music at the end of the tour.

My four years in medical residence resembled the words Goethe (in Faust) wrote years ago: "A man without satisfaction or inner peace, always striving." Looking back, the times of my medical residence when I was happy, the times when I was worried, and the times when I was exhausted have all become jumbled together. I often felt as if I was wandering, lost and trying to find my way. In those times there often would be a line from some of the few books that I had read would comfort me. Even when I could not find strength to wander more and my effort was insufficient, I realized I could relish the present. In the congress at Dubrovnik, Croatia this fall I was shown an even wider world I could wander through and explore.

In this city called the "pearl of the Adriatic' time seemed both too short and also on the other hand seemed to stand still like eternity. This jewel of the city gave me beautiful memories of exploring the area with my mother and a desire to study English more diligently. I am very grateful for all those who provided the opportunity to take part in this congress.

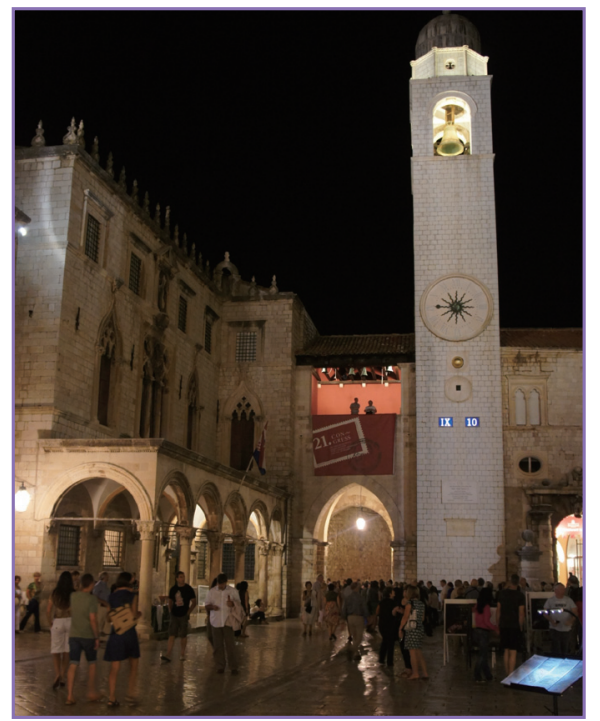

Fig. 4. Dubrovnik night view. 